\title{
Identifying Problems among Seabass Brackish-Water Cage Entrepreneurs in Malaysia
}

\author{
Khairuddin Idris ${ }^{1}$, Hayrol Azril Mohamed Shaffril ${ }^{2}$, Jeffrey Lawrence D'Silva ${ }^{2} \&$ Norsida $\mathrm{Man}^{3}$ \\ ${ }^{1}$ Faculty of Education, Universiti Putra Malaysia, Serdang, Malaysia \\ ${ }^{2}$ Institute for Social Science Studies, Universiti Putra Malaysia, Putra Infoport, Serdang, Malaysia \\ ${ }^{3}$ Faculty of Agriculture, Universiti Putra Malaysia, Serdang, Malaysia \\ Correspondence: Khairuddin Idris, Faculty of Education, Universiti Putra Malaysia, 43400 Serdang, Selangor, \\ Malaysia. E-mail: majudesa.desa@gmail.com; kidin@putra.upm.edu.my
}

Received: April 3, 2013 Accepted: May 16, 2013 Online Published: June 29, 2013

doi:10.5539/ass.v9n9p249 URL: http://dx.doi.org/10.5539/ass.v9n9p249

\begin{abstract}
As the strain on marine sources escalates, the aquaculture industry is becoming a viable alternative. Due to its potential to generate income for the community, interest in aquaculture is mounting. In line with this mounting interest, information with regards to the expected challenges within the industry serves as important preparation for future aquaculture entrepreneurs. Despite its importance, however, the availability of such data is lacking, and this study attempts to fill this gap by identifying the problems faced by the sea bass brackish-water cage entrepreneurs in Malaysia. The qualitative study uses in-depth interviews with aquaculture entrepreneurs who run sea bass rearing organizations at four different locations in Malaysia. Based on the analysis, four main themes are identified, namely financial, human factors, environmental and stakeholders. The ensuing discussion attempts to highlight points of interest for those who might venture into brackish-water cage aquaculture.
\end{abstract}

Keywords: aquaculture, community development, entrepreneurship

\section{Introduction}

China leads the aquaculture industry, with $66.7 \%$ of the global aquaculture stock being produced there, while $22.8 \%$ is produced in other Asian countries and the remaining 10.5\% is produced in the European and African continents ( $\mathrm{Li}$ et al., 2011). In accordance with the global trend, aquaculture is a flourishing industry in Malaysia. The rapid development of this industry has attracted local attention; it has become one of the most productive industries and has thereby enhanced the community's socio-economic development. As pressure on natural marine resources continues to increase, turning to aquaculture as an alternative resource is seen as an important step. The industry is gaining support from consumers as the demand for aquaculture products in Malaysia mounts (DOF, 2010). In acknowledging the importance of the industry to the country and the community, the Malaysian government has launched a number of schemes to encourage public involvement in the industry, such as Zone Industry Aquaculture High Impact Project (Note 1) and the e-Kasih Program (Note 2). In addition, a number of financial agencies, such as Agro Bank Malaysia, are offering loans with minimum interest for those who intend to venture into the industry. The impact of these efforts is clear, as the number of aquaculture entrepreneurs in Malaysia increased between 2008 and 2010. In addition, as a response to these programs and efforts, it can be seen that social acceptance of aquaculture among the public has increased (Faiz et al., 2010).

To further develop the industry, there has been an abundance of local and international studies, which focus in particular on the technical aspects of aquaculture. Nonetheless, researchers have devoted fewer attempts to the social aspects of aquaculture practices. In realizing this gap, this study's main objective is to explore the problems faced by sea bass aquaculture entrepreneurs in Malaysia. Furthermore, in line with the industry's development, there is a dire need to gather empirical evidence by which to understand and explain the challenges faced by aquaculture entrepreneurs, as it is vital to inform prospective stakeholders about the industry. It is a hoped that through this data, further knowledge on Malaysian aquaculture can be gained and healthy discussions can be derived for its continued development.

\subsection{Aquaculture in Malaysia}

As declining marine resources poses a threat to national food security, developing the aquaculture industry is 
seen as an attractive solution. The current development of the aquaculture industry in Malaysia reflects a positive trend, and production levels are able to meet local consumer demand. In Malaysia, the preferred type of aquaculture rearing method among local entrepreneurs is brackish-water cage farming. Among the main reasons for the preference is the stable market price of the resulting fish (Faiz et al., 2010). In 2010, for example, almost 2 million $\mathrm{m}^{2}$ were devoted to rearing brackish-water species. The industry has shown a steady growth, with the area used for brackish-water fish farming increasing to 1.74 million $\mathrm{m}^{2}$ in 2009 from 1.62 million $\mathrm{m}^{2}$ in 2008 (DOF, 2010).

The brackish-water cage industry has the potential to be one of the catalysts in uplifting the community's socio-economic level. As demonstrated by DOF (2010), the industry was able to create job opportunities for 2,445 local entrepreneurs in 2010; an increase of 502 from the number recorded in 2009. Though this number is comparatively small, the increasing trend recorded for aquaculture entrepreneurs is expected to persist, and this industry is expected to capture the public's interest, particularly among the young. The productivity of aquaculture is promising, and has already generated a steady source of income. In 2010, for example, a total of 2.8 million tons of brackish-water fish were harvested, generating a total of USD1.1 million for entrepreneurs (DOF, 2010).

Among the popular brackish-water species reared in Malaysia are sea bass, grouper, mangrove snapper and red snapper. The sea bass industry has been one of the important aquaculture endeavors to have contributed significantly towards improving the protein intake of Malaysians. In 2010, a total of 20,021 tons of sea bass were produced, generating almost USD0.33 million for entrepreneurs. In Malaysia, states such as Johor, Selangor and Pulau Pinang are the leading states in the production of farmed sea bass (DOF, 2010).

\section{Methodology}

This study employs a qualitative approach using in-depth interviews. The method enables an in-depth description of the problems faced by sea bass entrepreneurs in Malaysia. Furthermore, the study employed the generic approach to doing qualitative research (Marylin, 2006). The number of respondents was determined by the need for saturation. The saturation point is referred to as the moment at which a researcher arrives at an understanding of the experience, whereby it shall not be changed by further discussion with respondents (Laverty, 2003).

The researchers interviewed four sea bass entrepreneurs from four districts in Malaysia, namely Kuala Besut (a district in Terengganu), Lumut (a district in Perak), Kota Tinggi (a district in Johor) and Klang (a district in Selangor). All of the respondents are of different ages and experiences, and such differences provide some variation to the data for the researchers. To ensure that the questions asked were comprehended by the respondents, the interview was conducted in Malay language- the mother tongue of the respondents. The interviews were guided by an interview protocol which was developed earlier. It is essential to form such a protocol as it enables the use of a standard procedure for each of the respondents, while maintaining the flow of conversations. The key questions were initially prepared based on the literature relating to the experiences of aquaculture entrepreneurs. Four sea bass entrepreneurs were chosen as the respondents. The first was PL from Kuala Besut Terengganu, who was aged 50 years and had 16 years' experience of rearing sea bass. The second was BM from Lumut, who was aged 40 years and had six years' experience of rearing sea bass. The third respondent, $\mathrm{BD}$, aged 45, was from the southern part of Malaysia and had conducted his aquaculture activity in Kota Tinggi for three years. The last respondent, known as KL, was from Klang, was aged 35 and had been rearing sea bass for six years. Generally, the interviews took about one and a half to two hours, depending on how open and talkative the respondent was. The interviews began slowly with a short introductory chat through which to get to know the respondents' backgrounds. The questions prepared for the in-depth interviews were developed to meet the aim of this paper, which was to identify the problems faced by sea bass entrepreneurs in conducting their aquaculture activities. The questions served as a guide, allowing respondents freedom and flexibility in their answers. The data gained then were analyzed using thematic analysis.

\section{Results}

Rearing sea bass in cages is an attractive endeavor that can provide handsome returns. However, the industry has its challenges. The interviews revealed some of the problems faced by the entrepreneurs, and a number of themes emerged from the analysis.

\subsection{Financial Factors}

The increasing prices of pellets and fry seem to pose problems for the entrepreneurs, as the prices require increased capital and eat away at the entrepreneurs' profits. According to Ahmad Faiz et al. (2010), apart from diseases, entrepreneurs have mentioned the issue of high feed and fry costs to the authorities in the hopes that 
some form of price control can be put in place for these two inputs.

BD remarked, "The fish seedlings [used to be] only 40 to 50 cents [...] but now it reaches up to a ringgit and 50 cents for 4 inches [of] seedlings". In addition, the entrepreneurs were especially concerned about high feed costs. PL stated that:

For [a] thousand [fish], 25 kilos of pellet[s] is inadequate, three sacks of pellet[s] is inadequate, people said if we rely on the pellet[s] completely, we are 'finished' as our investment will not make [a] profit. Comparatively, if we use [...] trash fish, it is ok.

KL observed, "[over] a period of six years, the pellet price [has kept] increasing, [and] it shows no sign of decreasing". BM stated that the government should begin to pay attention to the caged fish industry. He maintained:

The fish need hundred[s of] kilos of pellet[s], though they said that fish are well developed if we feed them with the pellet[s]. It's true that the government has encouraged public involvement in agriculture, but we get less support from [...] them. Supposedly, entrepreneurs like us should be provided with subsidy[ies]. Why are we not given [a] pellet subsidy while the paddy farmers have received their fertilizer subsidy?

Among major issues commonly raised by the entrepreneurs in running their business was the limited access to small loans for the capital necessary to start their business. Responding to such issues can be important to ensure a thriving industry. Factors that impede the growth of the caged fish industry include labor availability and capital. Some entrepreneurs are willing to take chances when operating their ventures, although they may lack capital and operate on the hope that they can continue to finance growth from the profits reaped from their initial investments. BD illustrated the problem with capital as follows:

The current market is quite good. The main problem is [...] capital. [...] During the early stage[s of our business], our fish died and we were not able to make a profit and hence we [had] to start back [at the beginning].

The marketing of products is another big challenge that entrepreneurs need to overcome. In the beginning, entrepreneurs need to gain the trust and confidence of their buyers. The use of middlemen affords some marketing convenience for entrepreneurs; however, this can cut into profits (Shang et al., 1998). The respondents raised the marketing problems they have faced, such as their unwillingness to sign a marketing contract, or to use middlemen, the lack of access they have to Pasar Tani (Farmers Market), and the limited markets for their products.

I have received orders from hotel[s], they want[ed] the fish daily, [but I] was not willing to take the risk [at] that time as they ask[ed] us to sign a contract [which] clearly [stated] that they [would] sue me if I fail[ed] to meet the supply needed. (BD)

BD also reported that he had been short-changed by middlemen: "A couple months ago we used [...] middle[men]. They promised to pay us RM15 per kilo, nonetheless, after three days we only received RM12.50 per kilo". Entrepreneurs have to resort to the use of the middlemen when they are unable to sell their products. BM stated: "Actually, we use [...] middle[men], [because] the problem is that we cannot market our products at Pasar Tani".

\subsection{Human Factors}

In addition to middlemen, aquaculture entrepreneurs have to deal with losses through theft. The stealing of live fish from cages typically becomes more serious as the harvesting season approaches. Although the caged fish entrepreneurs may lose some of the fish to pests, such as birds and otters, poachers (which they refer to as "black-headed otters", in reference to the typically dark Asian hair), remain their biggest adversary. PL stated:

The Black-headed Otter is the most dangerous. Last year I had a thousand fish, ready to be harvested. We are waiting for the lorry to send [them] to the customer. However, the fish were stolen. There were only 40 kilos left in the cages, that tragedy made me cry!

BD also recalled his own encounter with thieves. He reported, "During my early years in this activity, there were cases [of theft]. One time, I went to my cages at $10.00 \mathrm{pm}$, I saw the thieves were fleeing on their boat once they realized my arrival at the cages". BM believed that the perpetrators in his case were locals: "I [reported them] at the police station, I suspected the thieves were $[\ldots]$ local villagers, it wasn't $[\ldots]$ outsiders”.

The manual work involved in rearing caged fish almost always requires assistance in the form of hired labor. The 
owner-operator will also then have to trust the hired labor to work whenever he goes away to deal with other aspects of his enterprise, such as purchasing and marketing. Ensuring workers' integrity, honesty and conscientiousness are essential if the venture is to provide good returns for the entrepreneurs. The owners have, however, encountered dishonest workers. As BM stated:

Foreign workers, about the time they are about to go back to their home countries, [...] will sell the fish to the dealers without informing their employers. It has happened to me. They sold the fish and took the money with them.

There have also been times when hired hands simply could not be relied upon to complete a task.

Once, I hired a new driver to [bring] my fish to the customers, I told him 'after two to three hours of journey, you should stop and check the water temperature, monitor the oxygen, ensure that the level of oxygen is suitable for the fish', but he was careless with the job. Once they arrived, most of the fish were dead. Only a few were still alive. (PL)

The caged-fish entrepreneurs sometimes hire relatives, but as some have found out, even relatives cannot always be trusted. "Previously, I [...] hired my nephew to take care [of] the cages, but sadly, he sold the fish and took the money, my own nephew".

A comprehensive financial record is an essential part of the aquaculture business, as it will ensure the organized operation of the business venture. Good record-keeping enables the operator to keep track of his production and financial activities. Despite the importance of this, however, the respondents seemed to adopt a casual attitude towards it, as illustrated by BM: "There is no systematic record for me, the record is only for me". PL conveyed a similar sentiment towards record keeping: "I only [write] my business record in a book. This week we sold a ton. Sometimes, officers from [the] Fisheries Department assist us in [writing] the record".

\subsection{Environmental Challenges}

Natural disasters are common in Malaysia (Tanggang, 2007). According to Wan Azli (2010), since the 1980s the number of days of extreme rainfall events in Malaysia has exceeded the 90th percentile of total rainfall at a number of meteorological stations, which results in floods in certain sensitive areas. Floods are one of the main threats brought about by the changing climate, and the disastrous impacts of this change have already been witnessed in Muar and Segamat in the east coast region in 2007. Such impacts have affected aquaculture activities, and a number of the respondents have experienced such changes.

Floods have also affected the income of aquaculture entrepreneurs. PL stated: "[we have] only 20 [fish] left, our main concern is the flood, in the past two years the flood has reduced our profits". Heavy, continuous rains that cause floods can wash away caged fish. However, floods are not the only problems for the entrepreneurs. Continuous rains also have adverse effects on the fish themselves, as BD commented: "if there is rain for three to four consecutive days, 24 hours a day, we are in deep trouble. [In the] last two years, I [have] reared 13,000 [fish]. Unfortunately, 9,000 [fish have] died after the rain". KL shares the same view: "The rain is too heavy and my fish cannot stand such weather condition[s]".

As most of the brackish-water cages are built on the river, which is home for a number of predators such as otters and egrets, the threats of these predators are almost inevitable. Fish is part of the otter and egret diet, and reared fish are easy prey for these predators. The respondents highlighted the threats brought by predators such as otters, egrets and, to some extent, other predator fish. The entrepreneurs reported that they have attempted various means by which to reduce the threats from these predators. However, they have not had much success. According to PL:

We $[\ldots]$ made a cover for the cage but the otters still manage to get inside [...] Some people said that lemongrass can get the otters away from the cage. Some said bath soaps can do the same thing, I've tried both and nothing has changed.

Apart from otters, the caged-fish producers also have to deal with birds that fly over the cages and catch the fish. Birds are more manageable, as KL indicated, "We cover the cages with net[s], [as] the egrets [fly] around here". The entrepreneurs also reported the infiltration of a sucker fish that the locals call ikan tempel, literally meaning latch fish. Ikan tempel are parasites and latch onto reared fish to feed on their blood. According to BD,

Yes, it suck[s] the blood, we realized it, we have 300 [fish] inside the cages, [and] once they [get]

bitten by ikan tempel, the fish will be uncomfortable and be less active than usual.

As the industry is rapidly developing in the country, the problem of disease has emerged. Disease is one of the major concerns in aquaculture activities, and it may impede the socio-economic development of the 
entrepreneurs (Bondad-Reantaso et al., 2005). Reared fish can become infected in three ways, namely through the introduction of exotic diseases, via sudden changes in the pattern of existing endemic diseases, or by the appearance of previously unrecognized diseases (Wei, 2002).

Within the local context, it seems that scale protrusion disease is the most common disease that infects sea bass. As the name suggests, the scales of the infected fish protrude outwards. PL confirmed: "Commonly, disease[s] such as scale protrusion, caligussp and stroke infect the fish". BD attributed the disease to salinity: "Usually it is $[\ldots]$ scale protrusion, probably because the water is too salty". Fish can also be infected with copepods (caligus sp.) that inevitably cause losses to the entrepreneurs. KL notes, "Wounded fish can easily be[come] infected once the caligussp [attach] to their body. Eventually the wound [will] worsen.

Obtaining high-quality seedlings is important, as this will contribute towards the entrepreneurs' productivity and income. Nonetheless, the ability to select quality seedlings poses challenges to the respondents, as most of them lack the skills to identify them. BD admitted that he only realizes the quality a month after he begins rearing the seedlings.

That's one of the problems, once the seedlings arrive, we do not know whether [they are] good or not. We shall know the quality only after we [rear] it for a month. This problem occurs as we are not the seedling producers. The highest quality seedlings, local entrepreneurs call [...] the 'Head', the second one, local entrepreneurs call [...] the 'Body', and the lower quality seedlings local entrepreneurs call [...] the 'Tail". I've bought 2000 seedlings and 500 of the $[\mathrm{m} \mathrm{...]}$ are the 'Tails'. (BD)

Intensive development in the industry and agriculture activities has introduced various pollutants into the aquatic ecosystem. Furthermore, aquaculture itself has been acknowledged as one of the major contributors to environmental degradation, if it is conducted without proper environmental precautions (Cole et al., 2009). In Malaysia, palm oil and rubber are two major commodities that are planted everywhere, including areas near to the aquatic ecosystem. One respondent voiced his concern on this matter: "There is an oil palm plantation over there. They use fertilizers and chemicals. Conditions are worsened if there is heavy rain [...] All these things will mix with the rain and flow into the river and pollute it".

$\mathrm{BM}$, whose fish cages are near an estuary, stated that industrial and other farming activities contribute to the degradation of the river. He commented: "The most suitable place for the industry is [an area] that is free from any industry. Here we have the shipping industry, in addition there is a pig farm [...] nearby".

\subsection{Stakeholders}

Support from the authorities plays a significant part in achieving success for most development projects planned for the community (Shaffril et al., 2010). Support can be financial, technical or social, and is needed by the aquaculture entrepreneurs as, according to them, it will aid them in their aquatic activities. BM gave his views on the type of support that he feels is important for the industry.

Actually, just like other branches of agriculture, we also need subsid[ies] for the tools, nets and pellets. Please don't give such things for those who don't have the 'heart' for this industry. Don't give it to a taxi driver and ask him to rear the fish. That is not right. It is crucial to give such things to those who are in the industry like us.

The expectations of entrepreneurs such as KL is that there should be some assistance from the agricultural authorities, who have provided entrepreneurs in some agricultural industries support in the form of grants, subsidies and technical expertise. "They have informed people on television that they want agriculture to flourish, but there is nothing for us. We have met them, the authorities, but there [was] lot of bureaucracy involved". BD claims that there has not been much support from the authorities so far. According to him, "Only once the officer came to my cages, [to measure them]. There [were] no more visit[s] from the officers after that".

Though entrepreneurs have had the opportunity to attain much knowledge from courses and seminars, not all the knowledge they learned from these sources can be applied to their aquaculture activities. They must prudently apply the knowledge according to the type of fish and cages they have. This is one the major problems faced by entrepreneurs, particularly the new ones. PL stated: "As entrepreneurs, if we attend courses, we do not easily accept all of the information given. Not all of the information given can be applied". He further added: "Courses are more inclined towards theories. They are two different things actually, things in [...] books and the practical [applications are] different". 


\section{Discussion and Recommendations}

Arguably, the financial factor is the most crucial component in ensuring the sustainability of certain businesses. In the case of aquaculture, it seems that the price of pellets and seedlings, and the lack of capital and marketing are the main issues faced by the operators. As the prices of these inputs keep escalating, price control from the authorities is viewed by some as a solution. Such control is important, as the entrepreneurs are relying almost completely on pellets as the main nutrient source for their fish. In addition, reasonable pellet and seedling prices will aid them in minimizing their capital expenditures, while maximizing their profits. In terms of capital, access to credit should be extended as it will provide opportunities for them to seek additional capital for their business. Moreover, the number of agencies that are able to offer low interest rates to the aquaculture entrepreneurs should be increased. To date, the Agro Bank is the only financial agency that offers zero interest to interested parties. Marketing is a common issue faced by entrepreneurs in any business. In the case of the aquaculture industry, the Federal Agriculture Marketing Authority (FAMA) should include aquaculture outputs as one of the products it markets. FAMA is a government agency whose main target is to develop an efficient and effective food and agricultural marketing chain in order to sustain customer value.

Human behavior is another issue raised by the entrepreneurs. However, there are certain aspects of human behavior that can be managed in the form of preventive actions that are taken into consideration and planned during the earlier stages of the project. Stealing, for example, can be addressed if continuous means of monitoring are in place at the cages, and by hiring people who are trusted and capable of doing the job. In addition, mutual cooperation among the aquaculture community can contribute towards a systematic and planned rotation system in monitoring the cages.

The relatively technical nature of the aquaculture industry requires specialist knowledge. Owners and operators also need to keep their knowledge updated on the current demands of the industry. A number of knowledge-sharing forums and technical training sessions should be made available to the owners, operators and workers, particularly on integrity and good aquaculture practices, technical aquaculture aspects, and keeping sufficient financial records. Some of the entrepreneurs questioned the usefulness of certain information and practices they have been exposed to, and they should thus be advised on the reliability and validity of it. Organized forums could also serve as a platform for all of the community including the entrepreneurs to share knowledge and find solutions to current mutual problems (Hassan et al., 2011).

Challenges posed by the natural environment can be undesirable and unpredictable. Climatic changes may have disastrous impacts on both the people and the industry. As the brackish-water cage industry is conducted on rivers, the vulnerability of the cages towards the threats of such changes is high. Similarly, within the scope of aquaculture, the impacts relating to floods has raised concern among the local entrepreneurs. The disastrous flood in 2007, for example, affected a number of areas in Johor, Kedah and Terengganu, and resulted in the losses of millions of Ringgits to the agricultural sectors, including aquaculture. As the climate is predicted to keep changing, adaptation in this regard is seen as an effective preventive action (Shaffril et al. 2011). Adaptation to climate change should assist the communities or the ecosystem to cope with actual or expected impacts of it. Referring to Shaffril et al. (2013) and Shemsanga et al. (2010), strategies such as diversifying sources of income, widening access to credit, strengthening the community's social relationship and local involvement in adaptation planning can construct a solid adaptation strategy for the community.

Predators such as otters and egrets can reduce the entrepreneurs' profits, and again continuous monitoring can be practiced to overcome such problems. In addition, usage of better tools such as thick nets to cover the cages is expected to lessen the threats. In terms of diseases and seedling quality, frequent monitoring by the fisheries authority is needed. Information should be disseminated with regards to diseases, along with methods of prevention, treatment and safe drugs. This information will keep entrepreneurs up-to-date on the required actions during infection, as well as assisting them to prepare for facing the threats of such diseases. Providing entrepreneurs with information on methods for detecting seedling quality at earlier stages is also crucial, as this will help them to select only the best seedlings for their cages. Furthermore, such information can be effectively disseminated to them via traditional sources such as television, radio and newspapers as these sources are considered as trusted and reliable among the community particularly those in the rural areas (Hassan et al., 2011). Within the local setting, it will be an advantage if they are able to determine quality seedlings, as it will ensure that entrepreneurs can maximize their profits.

The relationship between the authorities and aquaculture entrepreneurs should be strengthened, as it is seen as the key for increasing national aquaculture productivity (Faiz et al., 2010). Production support, such as subsidies for pellets and seedlings, can relieve entrepreneurs of some of their capital outlay. Officers from the fisheries 
department, for example, could spend more time in the field as this would strengthen their relationship with the entrepreneurs. Continuous monitoring from them is crucial, as this will help to prevent pollution within areas in which aquaculture activities are conducted.

Overall, aquaculture owners, operators and stakeholders have the potential to fare well as an organized community. As in most agricultural industries, the formation of an interest group that takes care of and speaks for the aquaculture entrepreneurs may bode well for the industry.

\section{Conclusion}

The aquaculture industry is an important branch of the fisheries sector. Statistics have shown the effectiveness of this industry in fulfilling the role of strengthening the community's socio-economic aspects. As interest in the industry from the community is mounting, delivering data with regards to expected problems becomes pertinent. Nonetheless, the availability of such data is scarce, particularly on the rearing of sea bass. Within the scope of this industry, failure to respond to the problems and contradictions at an early stage will pose bigger future challenges for the entrepreneurs. Based on the interviews conducted, a number of themes have been created for the problems faced by the sea bass entrepreneurs in Malaysia, namely financial, human factors, environmental and stakeholders. Exposure to seminars and training, disseminating technical information and creating strong relationships between the authorities and the sea bass entrepreneurs, as well as the formation of a producers' interest group, are seen as a crucial step to overcoming the problems mentioned. The study has two major contributions. First, the findings can be referred by the concern parties as information sources in generating aquaculture related policy making or aquaculture development strategies.Second, the findings from this study can contribute towards the existing literatures and provide a basis for future studies with regard to the aquaculture industry. It is suggested that future studies should be focused specifically on the socio-economic impacts of the changing climate on the entrepreneurs and the aquaculture areas which have a higher vulnerability towards the changing climate (e.g. Kuala Besut in Terengganu). To have such studies is vital as past studies conducted by Wai et al. (2005), Wan Azli (2010) and Intergovernmental Panel on Climate Change has predicted that the climate change phenomenon in Malaysia is worsening. The study is limited in a sense that it is only conducted among aquaculture entrepreneurs four aquaculture areas in Malaysia and the results might be enriched if entrepreneurs from other aquaculture areas are included.

\section{References}

Abu Hassan, M., Hassan, M. S., Shaffril, H. A. M., \& D’Silva, J. L. (2009). Problems and obstacles in using information and communication technology among Malaysian Agra-based entrepreneurs. European Journal of Scientific Research, 36(1), 93-101.

Ahmad Faiz, A. N., Khairuddin, I., Shaffril, H. A. M., \& D’Silva, J. L. (2010). Aquaculture industry potential and issues: a case from cage culture system entrepreneurs: suggestions for intensification of aquaculture industry. Journal of Social Science, 6(2), 206-211.

Bondad-Reantaso, M., Subasinghe, R. P., Arthur, J. R., Ogawa, K., Chinabut, S., Adlard, R., Tan, Z., \& Shariff, M. (2005). Disease and health management in Asian aquaculture. Vet. Parasitol., 132, 249-272. http://dx.doi.org/10.1016/j.vetpar.2005.07.005

Cole, D. W., Cole, R., Gaydos, S. J., Gray, J., Hyland, G., Jacques, M. L. ... Au, W. W. (2009). Aquaculture: environmental, toxicological, and health issues. International Journal of Hygiene and Environmental Health, 212, 369-377. http://dx.doi.org/10.1016/j.ijheh.2008.08.003

Creswell, J. W. (2007). Qualitative inquiry and research design: Choosing among five traditions (2nd ed.). Thousand Oaks, CA: Sage Publications.

Department of Fisheries Malaysia (DOF). (2010). Statistics on Aquaculture. Retrieved September 24, 2012, from http://www.dof.gov.my/html/themes/moa_dof/documents/jadual_pendaratan_marin_\%20aquaculture.pdf.

Hassan, M. S., Yassin, S. M., Shaffril, H. A. M., Othman, M. S., Abu Samah, B., Abu Samah, A., \& Ramli, S. A. (2011). Receiving the Agriculture Information through Mass Media and Interpersonal Sources among the Rural Community. American Journal of Agriculture and Biological Science, 6(3), 451-461. http://dx.doi.org/10.3844/ajabssp.2011.451.461

International Panel on Climate Change (IPCC). (2007). Climate change: impact, adaptation and vulnerability, Contribution of Working Group II to the Fourth Assessment Report of the Intergovernmental Panel on Climate Change. Cambridge University Press, Cambridge.

Laverty, S. M. (2003). Hermeneutic phenomenology and phenomenology: A comparison of historical and 
methodological considerations. International Journal of Qualitative Methods, 2(3), 21-35.

Li, X., Li, J., Wang, Y., Fu, F., Li, B., \& Jiao, B. (2011). Aquaculture industry in China: current state, challenges, $\begin{array}{lllll}\text { and } & \text { outlook. Reviews in }\end{array}$ http://dx.doi.org/10.1080/10641262.2011.573597

Marilyn, L. (2006). Qualitative research in education: a user's guide. Thousand Oaks, CA: Sage Publications.

Marshall, C., \& Rossman, C. B. (2011). Designing Qualitative Research (5th ed.). Thousand Oaks, CA: Sage Publications.

Shaffril, H. A. M., Abdul Nasir, A. F., Idris, K., Uli, J., \& D'Silva, J. L. (2010). Agriculture project as an economic development tool to boost the socio-economic level of the poor community: The case of Agropolitan project in Malaysia. African Journal of Business Management, 4(11), 2354-2361.

Shaffril, H. A. M., Abu Samah, B., D’Silva, J. L., \& Yassin, S. M. (2013). The process of social adaptation towards climate change among Malaysian fishermen. International Journal of Climate Change Strategies and Management, 5(1), 38-53. http://dx.doi.org/10.1108/17568691311299354

Shaffril, H. A. M., Abu Samah, B., Uli, J., \& D'Silva, J. L. (2011). Global warming at the east coast zone of peninsular Malaysia: what fishermen say about it. American Agriculture and Biology Science, 6(3), 377-383. http://dx.doi.org/10.3844/ajabssp.2011.377.383

Shang, Y. C., Leung, P., \& Ling, B. (1998). Comparative economics of shrimp farming in Asia. Aquaculture, 164(1-4), 183-200. http://dx.doi.org/10.1016/S0044-8486(98)00186-0

Shemsanga, C., Omambia, A. N., \& Gu, Y. (2010). The cost of climate change in Tanzania: impacts and adaptations. American Sciences, 6(3), 182-196.

Tangang, F. (2007). Climate change and global Warming: Malaysia perspective and challenges. Paper presented at UKM Public Speech, Anuar Mahmud Hall, Universiti Kebangsaan Malaysia.

Wai, N. M., Carmelengo, A., \& Ahmad Khairi, A.W. (2005, June). A study of global warming in Malaysia. Journal of Technology, 42, 1-10.

Wan Azli, W. H. (2010). Influence of climate change on Malaysia weather pattern. Paper presented at Malaysia Green Forum 2010 (MGF2010), 26-27 April, 2010, Putrajaya, Malaysia.

Wei, Q. (2002). Social and economic impacts of aquatic animal health problems in aquaculture in China. In J. R. Arthur, M. J. Phillips, R. P. Subasinghe, M. B. Reantaso, \& I. H. MacRae (Eds.), Primary Aquatic Animal Health Care in Rural, Small-Scale, Aquaculture Development (pp. 55-61). FAO Fisheries Technical Paper No. 406. Rome, Italy: FAO.

\section{Notes}

Note 1. The Zone Industry Aquaculture High Impact Project is a program for zoning land and coastal areas that have been identified as suitable for the development of commercial-scale aquaculture projects.

Note 2. One of the programs to double the productivity of fish, prawns and shellfish, as stated in the Third National Agriculture Policy (DPN3).

\section{Copyrights}

Copyright for this article is retained by the author(s), with first publication rights granted to the journal.

This is an open-access article distributed under the terms and conditions of the Creative Commons Attribution license (http://creativecommons.org/licenses/by/3.0/). 